\title{
Antivirals against human and animal Coronaviruses: different approach in SARS-CoV-2 treatment
}

Igor de Andrade Santos' ${ }^{1}$, Victória Riquena Grosche ${ }^{1}$, Robinson Sabino-Silva ${ }^{2}$ and Ana Carolina Gomes Jardim ${ }^{1,3^{*}}$.

${ }^{1}$ Laboratory of Virology, Institute of Biomedical Science, Federal University of Uberlândia, MG, Brazil

${ }^{2}$ Department of Physiology, Institute of Biomedical Sciences, Federal University of Uberlândia, Minas Gerais, Brazil

${ }^{3}$ São Paulo State University, IBILCE, São José do Rio Preto, SP, Brazil

\section{* Correspondence:}

Corresponding author: Professor Ana Carolina Gomes Jardim

E-mail: jardim@ufu.br

Institute of Biomedical Science, ICBIM/UFU, Avenida Amazonas, 4C- Room 216, Umuarama, Uberlândia, Minas Gerais, Brazil, CEP: 38405-302

Tel: +55 (34) 3225-8682

Keywords: antivirals, coronaviruses, COVID-19, SARS-CoV-2, treatment. 


\title{
Antivirals against human-animal Coronaviruses
}

\begin{abstract}
Coronaviruses (CoVs) is a group of viruses from Coronaviridae family which are able to infect human and animals, causing mild to severe disease. The recently emergence of SARS-CoV-2, worldwide classified as a pandemic disease represent a threat to global public health. Associated with the high transmissibility, the lack of vaccine and antivirals drugs demonstrates the need to develop novel therapies to treat infected patients. This review aims to summarize compounds from 2005 up to now with already described antiviral activity in vitro and in vivo to human and animal CoVs. These compounds may present as a source of molecules with potent biological activities which could be further investigated for their use as novel approaches against SARS-CoV-2.
\end{abstract}




\section{INTRODUCTION}

Coronaviruses (CoVs) were first identified in 1960 (Kahn and McIntosh, 2005) and were classified as a members of the family Coronaviridae. CoVs are enveloped, single-stranded RNA viruses with a genome varying from 25 to $32 \mathrm{~kb}$ (Payne, 2017). Viral structure is primarily formed by the structural proteins such as spike $(\mathrm{S})$, membrane $(\mathrm{M})$, envelope $(\mathrm{E})$, and nucleocapsid $(\mathrm{N})$ proteins, and hemagglutinin-esterase (HE) protein in some CoVs. The S, M, and E proteins are all embedded in the viral envelope, a lipid bilayer derived from the host cell membrane. The $\mathrm{N}$ protein interacts with the viral RNA in to the core of the virion (Figure 1) (Fehr and Perlman, 2015).

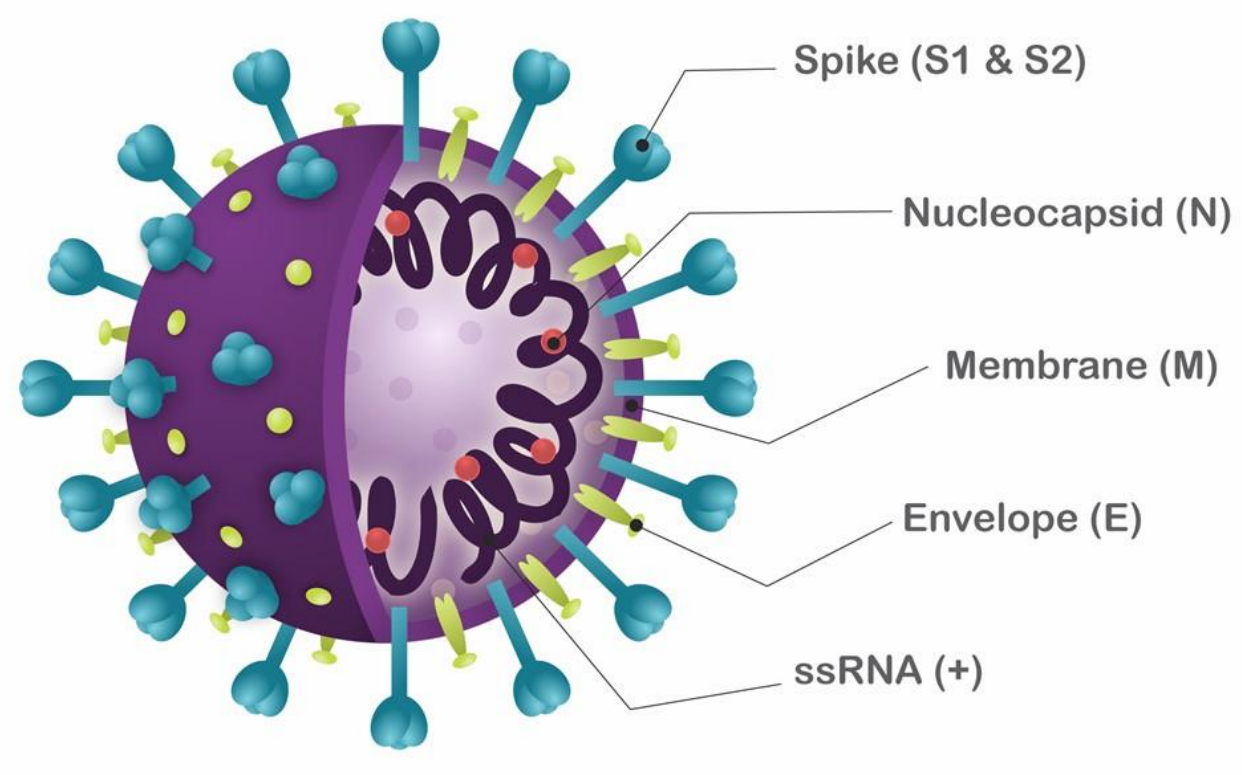

\section{SARS-CoV-2}

Figure 1: Schematic structure of SARS-CoV-2

These viruses are able to infect vertebrate animals causing acute and chronic disease in respiratory, cardiac, enteric and central nervous systems, both in humans and animals (Weiss and Navas-Martin, 2005). In animals, the most common CoVs are infectious bronchitis virus (IBV), feline $\mathrm{CoV}(\mathrm{FeCoV})$ and mouse hepatitis virus (MHV), which infects chickens, felines and rodents, respectively (Cui et al., 2019). That are seven known CoVs that can cause diseases in humans: HCoV229E, HCoV-NL63, HCoV-OC43, HCoV-HKU1, severe acute respiratory disease coronavirus (SARS-CoV), middle east respiratory syndrome coronavirus (MERS-CoV) and, recently SARS-CoV2 (Graham et al., 2013; CDC, 2020). The CoVs HCoV-229E, HCoV-NL63, HCoV-OC43, HCoV- 


\section{Antivirals against human-animal Coronaviruses}

HKU1 cause mild symptoms, similar to a common cold (Payne, 2017). However, SARS-CoV, MERS$\mathrm{CoV}$ and SARS-CoV-2 can cause mild to severe symptoms related to upper respiratory infection as fever, cough, dyspnea, pneumonia and severe acute respiratory syndrome (SARS), and even death (Lai et al., 2020).

CoVs are linked to a zoonotic transmission for their ability to infect different species. It can lead to host jumps, allowing the emergence of a new coronavirus as SARS-CoV, MERS-CoV and SARS-CoV-2 (Lu et al., 2015; Reusken et al., 2016; Andersen et al., 2020). The transmission of CoVs is based on fecal-oral route in animals (Kipar et al., 2010). In humans, the CoVs transmission can occur by direct contact with droplets when an infected person and a recipient person are in close contact (within $1 \mathrm{~m}$ ). These infective oral and respiratory droplets produced by talking, coughing, sneezing of infected person need contact the mucosae (mouth and nose) or conjunctiva (eyes) of recipient person. Additionally, the indirect transmission can occur by touching a surface with viable CoV and subsequent contact with mouth, nose or eyes (Doremalen et al., 2020).

Recently, the SARS-CoV-2 emergence was related to zoonotic transmission, but is not clear how this virus was first transmitted to humans (Andersen et al., 2020; Gorbalenya et al., 2020b). By phylogenetic analysis, the SARS-CoV-2 was grouped with bat SARS-related coronaviruses, suggesting host jump (Cao et al., 2020; Lai et al., 2020). The high transmissibility of this new CoV allowed the rapid and efficient spread of the virus across the world, becoming a pandemic disease in a few months (CDC, 2020; Wu et al., 2020).

There is a lack of understanding on SARS-CoV-2 replication in host cells, and the complete mechanism remains to be discovered. However, the knowledge about other CoVs may suggest how SARS-CoV-2 entry in host cell, replicates and is released. The SARS-CoV-2 virion entries the host cells by attaching of S protein in angiotensin converting enzyme 2 receptor (ACE2) (Hoffmann et al., 2020; Tai et al., 2020). An acid-dependent proteolytic cleavage of the $\mathrm{S}$ protein by cellular proteases, like cathepsin, TMPRRS2 and trypsin, allows the attachment in ACE2 and, subsequently, fusion of the viral envelope to cellular membranes. (Belouzard et al., 2009; Matsuyama et al., 2020). In the cytoplasm the $\mathrm{CoV}$ viral genome is uncoating and the viral RNA is released in host cell. The viral genomic which is a positive-sense RNA is translated to produce nonstructural proteins (nsps) from two open reading frames (ORFs), ORF1a and ORF1b. The ORF1a encodes the polypeptide pp1ab that is cleaved in $11 \mathrm{nsps}$, while the ORF1b encodes the polypeptide pp1ab which is cleaved into $16 \mathrm{nsps}$. The proteolytic cleavage is made by viral proteases nsp3 and nsp5 (Yogo et al., 1977; Lai and 
Stohlman, 1981; Kim et al., 2020). The nsps assemble to form a replicase-transcriptase complex (RTC) responsible for RNA synthesis, replication and transcription of sub-genomic RNAs (Fehr and Perlman, 2015). Sub-genomic RNAs will perform as mRNAs for structural and accessory genes localized downstream of the replicase polyproteins. SARS-CoV-2 has 6 accessory proteins: 3a, 6, 7a, 7b, 8 and 10 (Kim et al., 2020). The structure proteins S, E and M are translated from the subgenomic RNAs and forwarded to the endoplasmic reticulum (ER), and, subsequently, inserted in an intermediate compartment of ER with Golgi. There, viral genomes will be encapsulated by $\mathrm{N}$ proteins and assembled with the structural proteins and form a mature virion (Siu et al., 2008; Fehr and Perlman, 2015). The $\mathrm{M}$ proteins is known to binds to E protein and nucleocapsid, then, the $\mathrm{S}$ protein is incorporated into virions, forming a complete virion. Finally, the virions are transported to the cell surface in vesicles and released in pathway mediated by exocytosis (Figure 2) (Fehr and Perlman, 2015).

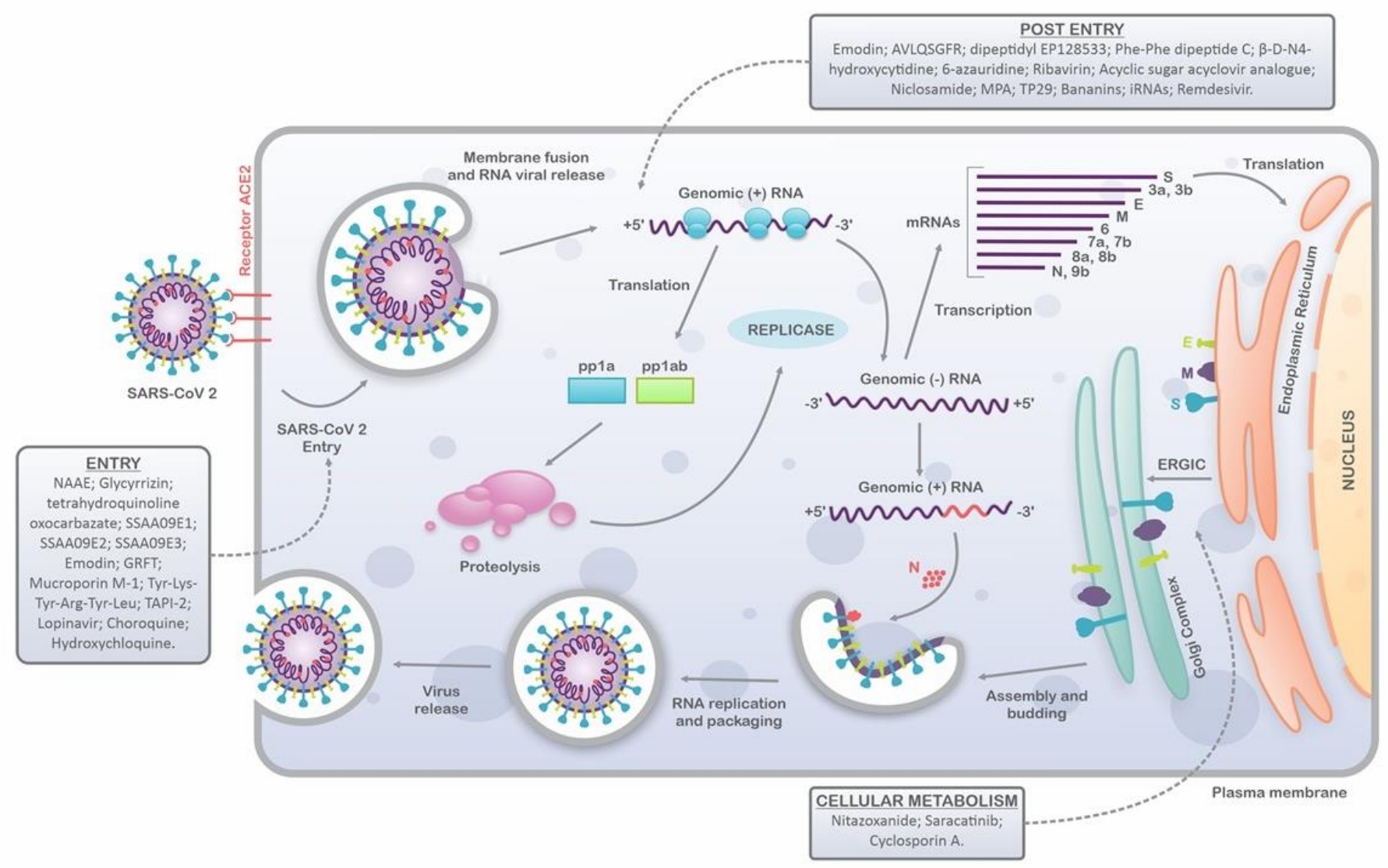

Figure 2: Schematic representation of SARS-CoV-2 replication cycle in host cells. Compounds with antiviral activity against SARS-CoV-2 are indicated in each step of virus replication cycle.

SARS-CoV-2 shows different epidemiological and clinical characteristics from the other epidemics of SARS-CoV and MERS-CoV (Ceccarelli et al., 2020; Gorbalenya et al., 2020b, 2020a). 
The high transmissibility of SARS-CoV-2 may be related to its entry on host cells (Sun et al., 2020). Both the SARS-CoV and SARS-CoV-2 glycoprotein S attaches to the ACE2 to entry the host cells. However, SARS-CoV-2 binds to ACE2 with higher affinity then SARS-CoV (Sun et al., 2020; Yan et al., 2020), enhancing infection. Bearing in mind the closely sequence identity of S1 and S2 and the possible overlap with 1.2 Å root-mean-square deviation at 417 position (Lusvarghi and Bewley, 2016), it is could explain the 10- to 20-fold higher kinetics affinity of SARS-CoV-2 ectodomain than SARSCoV ectodomain using surface plasmon resonance analysis (Wrapp et al., 2020). As other RNA virus, SARS-CoV-2 has an intrinsic genetic variability which promotes a high mutation ratio, allowing a more efficient adaptation to the environment (Duffy, 2018).

The high transmissibility and viral variability of the novel SARS-CoV-2, associated with the lack of vaccine drugs to treat the infected patients, threaten the global health system. Therefore, the development of effective antiviral is critical to bring short-term therapies able to reduce the severity of clinical outcomes and to reduce the spread of COVID-19. Here, we aimed to summarize compounds from 2005 up to now with already described antiviral activity in vitro and/or in vivo against human or animal CoVs. These compounds may present as a source of molecules with potent biological activities, which could be further investigated for their use as novel approaches against SARS-CoV-2.

\section{INHIBITORS OF CoVs REPLICATION}

\section{Inhibitors of CoVs entry}

Since the entry of human CoVs in to host cells is mainly related to the binding of viral S protein to the ACE2 receptor (Prabakaran et al., 2004; Sun et al., 2020), compounds that affect this interaction could be potential antivirals (Prabakaran et al., 2004). The molecule N-(2-aminoethyl)-1 aziridineethanamine (NAAE) showed the highest docking grade among 140.000 screened molecules provided by in silico molecular docking. The activity of NAAE was confirmed by in vitro enzymatic inhibitory activity on ACE2 and for their ability to inhibit SARS-CoVs spike protein-mediated cell fusion. In this structure-activity relation study, the molecules with the highest predicted binding scores were identified and assayed for ACE2 enzymatic inhibitory activity and by the enabling to suppress SARS-CoV S protein-mediated cell fusion (Huentelman Matthew J. et al., 2004). Also, Glycyrrizin, a major constituent from licorice root (Ramos-Tovar and Muriel, 2019), demonstrated antiviral activity inhibiting SARS-CoV entry in to Vero cells with an EC50 and CC50 of $300 \mathrm{mg} / \mathrm{mL}$ and > 20.000 $\mathrm{mg} / \mathrm{mL}$, respectively. The glycyrrizin was less effective when the administration occurs during the 


\section{Antivirals against human-animal Coronaviruses}

adsorption period compared to the intracellular period after entry in to host cells. Glycyrrhizin had additional effects when was administrated both during and after entry in host cells, which indicates a significantly potent inhibitor of virus. (Cinatl et al., 2003). The association of conjugates in the chemical structure of glycyrrizin produced an acid derivative, which were more potent inhibiting SARS-CoV (Hoever et al., 2005). It was demonstrated the effective reduction of SARS-CoV entry in 293T cells by the compound tetrahydroquinoline oxocarbazate, an oxocarbazate inhibitor of cathepsin L, with a EC50 of 273 nM (Shah et al., 2010). Additionally, an extensive work screened a library of compounds following the Lipinski's rule (Lipinski et al., 2001) and identified 3 noncytotoxic compounds capable of inhibiting SARS-CoV pseudoparticles entry in to 293T cells: i) SSAA09E1 blocks early interactions of SARS-CoV S protein with ACE2 (EC50 of 6.7 $\mu \mathrm{M}$ and CC50 >100 $\mu \mathrm{M})$; ii) SSAA09E2 affects cathepsin L activity (EC50 of 3.1 $\mu \mathrm{M}$ and CC50 > 100 $\mu \mathrm{M})$ and iii) SSAA09E3

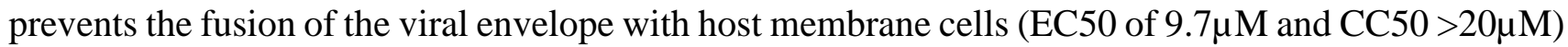
(Adedeji et al., 2013).

Other compounds also demonstrated to inhibited CoVs entry. Emodin is a component from Rheum officinale roots which inhibited the infectivity of S protein-pseudotype retrovirus from SARSCoV in Vero cells (Ho et al., 2007). Besides of the entry activity, Emodin demonstrated to possess post-entry activity, affecting $3 \mathrm{a}$ viral protein which is related to ion channels in infected Vero cells (Schwarz et al., 2011).

The griffithsin (GRFT) is a protein isolated from the red alga Griffithsia sp. and is a powerful viral entry inhibitor with activity against several enveloped viruses, as its antiviral activity against the human immunodeficiency virus (HIV). GRFT is capable to bind in terminal mannoses of oligosaccharides and also in glycans on the surface of the viral envelope glycoproteins (Lusvarghi and Bewley, 2016). GFRT did not show cytotoxicity in Vero cells, human ileocecal colorectal adenocarcinoma cells, human diploid fibroblast cells and rhesus monkey kidney cells. It broadspectrum antiviral activity was seen, inhibiting SARS-CoV (EC50 of $0.61 \mu \mathrm{g} / \mathrm{mL}$ ), bovine coronavirus (BCoV) (EC50 of $0.057 \mu \mathrm{g} / \mathrm{mL}), \mathrm{MHV}$ (EC50 of $0.23 \mu \mathrm{g} / \mathrm{mL}), \mathrm{HCoV}-\mathrm{OC} 43$ (EC50 of $0.16 \mu \mathrm{g} / \mathrm{mL}$ ), HCoV-229E (EC50 of $0.18 \mu \mathrm{g} / \mathrm{mL}$ ) and HCoV-NL63 (EC50<0.032 $\mu \mathrm{g} / \mathrm{mL}$ ) in in vitro assays (O'Keefe et al., 2010). In another study, GRFT inhibited entry steps of MERS-CoV infection in HEK293T cells (Millet et al., 2016). Furthermore, GRFT improved surviving in mice infected with SARS$\mathrm{CoV}$ and protected the animals from infection by binding with S protein (O'Keefe et al., 2010). 


\section{Antivirals against human-animal Coronaviruses}

Altogether, GRFT could be considered as a potential SARS-CoV-2 entry inhibitor with activity against E proteins.

Cationic antimicrobial peptides (AMPs) has also been considered a potential broad-spectrum antiviral agent. From compounds isolated from animals, mucroporin is a AMP found in scorpions venom of Lychas mucronatus (Dai et al., 2008). The optimized derivative mucroporin-M1 inhibits MeV, SARS-CoV and influenza H5N1. Specifically, mucroporin M-1 affected SARS-CoV entry with EC50 of $14.46 \mu \mathrm{g} / \mathrm{mL}$ and CC50 of $61.58 \mu \mathrm{g} / \mathrm{mL}$, by a virucidal activity in HeLa-ACE2 cells. (Li et al., 2011).

Struck and colleges using bioinformatics tools predicted and synthetized sixteen peptides as ligand for receptor binding domain (RDB) present in S proteins of CoVs. Of the sixteen peptides, the hexapeptide (Tyr-Lys-Tyr-Arg-Tyr-Leu) inhibited the SARS-CoV and H-CoV-NL63 infection in Vero cells, without triggering cytotoxicity (Struck et al., 2012).

Some other factors are needed in order to assist the entry of virus in hosts cells, as the cellular factor TNF- $\alpha$ converting enzyme (TACE) which facilitates the SARS-CoV entry (Haga et al., 2008). TAPI-2, a TACE inhibitor, is a potent antiviral compound that promoted the blockade of $65 \%$ in the SARS-CoV entry in HEK-293T cells. However, the compound did not affect the virus titer in in vivo assays (Haga et al., 2010).

\section{Inhibitor of post-entry replication steps of CoVs}

Main proteases (Mpro) are produced during viral replication, as chymotrypsin-like protease (3CLpro) and papain-like proteases (PPL), which are key step enzymes in the replication of CoVs (Anand et al., 2003). Therefore, these enzymes are very attractive targets for drug development against CoVs. In this context, Gan and coworkers used molecular docking method to select the octapeptide AVLQSGFR as a Mpro inhibitor of SARS-CoV, and evaluated its antiviral activity in infected Vero cells. The octapeptide AVLQSGFR demonstrated an EC50 of 2.7 x 10 ${ }^{-2} \mathrm{mg} / \mathrm{mL}$ and a CC50 > 100 $\mathrm{mg} / \mathrm{mL}$, resulting on a selectivity index of over 3704 (Gan et al., 2006). Five computer modeling PhePhe dipeptide inhibitors (A-E) were designed to interact with 3CLpro. All of them were active protecting Vero cells from cytopathic effect (CPE) caused by SARS-CoV, however, the C analogue showed the most potent activity with EC50 of 0,18 $\mu \mathrm{M}$ and CC50 > $200 \mu \mathrm{M}$ (Shie et al., 2005). The dipeptidyl EP128533 is another protease inhibitor (Zhang et al., 2006) that showed antiviral activity against SARS-CoV, with a EC50 and CC50 of $1.4 \mu \mathrm{g} / \mathrm{mL}$ and $>100 \mu \mathrm{g} / \mathrm{mL}$, respectively. However, it 
was not efficient in reducing effects of viral replication in BALB/c mice (Day et al., 2009). In other study, it did not present activity on SARS-CoV in Vero and $\mathrm{CaCO}_{2}$ cells (Zhang et al., 2006).

In viral replication, the RNA-dependent RNA polymerase ( $\mathrm{RdRp})$ is responsible for catalyzing the replication of the viral RNA using an RNA template. Compounds that interfere in this process could be candidate drugs for treating viral infections (Ganeshpurkar et al., 2019). Nucleoside analogs as Pyrimidine interferes in UTP metabolism, directly affecting viral replication (Murphy and Middleton, 2012), as demonstrated by $\beta$-D-N ${ }^{4}$-hydroxycytidine interfering in SARS-CoV (EC50 of $10 \mu \mathrm{M}$ and CC50 > $100 \mu \mathrm{M}$ ) and HCoV-NL63 (EC50 of $400 \mathrm{nM}$ and CC50 > $100 \mu \mathrm{M}$ ), and also, 6-azauridine inhibiting HCoV-NL63 replication ( EC50 of 32 nM and CC50 of $80 \mu \mathrm{M}$ ) (Barnard et al., 2004; Pyrc et al., 2006). Some 2-(benzylthio)-6-oxo-4-phenyl-1,6-dihydropyrimidine derivatives were designed (compounds $6 \mathrm{a}-\mathrm{n}$ ) to inhibit SARS-CoV activity. The inhibitory potency of compound $6 \mathrm{~m}$ as a SARS$\mathrm{CoV}$ 3CL pro-inhibitor was related to the presence of pyrimidine unit in molecular structure (Ramajayam et al., 2010).

Ribavirin is another synthetic nucleoside analogue used for treatment of patients chronically infected by hepatitis C virus (PubChem, 2005c). Ribavirin has antiviral activity already described against many RNA viruses and demonstrated to be a broad-spectrum antiviral for CoVs (Chan et al., 2013). Its activities were described for SARS-CoV in vitro (EC50 of $20 \mu \mathrm{g} / \mathrm{mL}$ and CC50>200 $\mu \mathrm{g} / \mathrm{mL}$ ), but it did not reduce viral load in in vivo assays with BALB/c mice (Saijo et al., 2005; Barnard et al., 2006). Ribavirin did now show good results for the treatment of critically MERS-CoV patients (Al-Tawfiq et al., 2014). Additionally, a nucleoside analogue based on acyclic sugar scaffold of acyclovir showed powerful antiviral activity against MERS-CoV (EC50 and CC50 of $23 \mu \mathrm{M}$ and 71 $\mu \mathrm{M}$, respectively) and HCoV-NL63 (EC50 and CC50 of $8.8 \mu \mathrm{M}$ and $120 \mu \mathrm{M}$, respectively) (Peters et al., 2015).

As others options in post-entry stages, Niclosamide, a drug used in antihleminthic treatment (Katz, 1977), demonstrated antiviral activity on post-entry steps of SARS-CoV replication in Vero cells, with an EC50 of 1-3 $\mu \mathrm{M}$ and CC50 of 250 $\mu \mathrm{M}$ (Wu et al., 2004). Mycophenolic acid (MPA), an antibiotic derived from penicillium fungal species (PubChem, 2005b) also demonstrated to inhibit MERS-CoV replication in Vero cells with EC50 of 2.87 $\mu \mathrm{M}$. However, MPA was not active against SARS-CoV both in in vitro and in vivo assays (Cinatl et al., 2003; Barnard et al., 2006). 


\section{Antivirals against human-animal Coronaviruses}

The nonstructure protein 10 (nsp10) of CoVs were described as responsible for a stimulatory effect on nsp16, a classical S-adenosylmethionine-dependent (nucleoside-2'-O)-methyltransferase that act in RNA binding or catalysis. TP29 peptide was designed as a ligand interaction to nsp10 of MHV and demonstrated to have a broad-spectrum activity, inhibiting SARS-CoV and MHV replication in both infected cell lines and mice (Wang et al., 2015). Bananins is a class of adamantanes conjugated with pyridoxal (vitamin B6) (Kesel, 2003) that showed an effective inhibition of SARS-CoV in FRhK4 cells, with EC50 < $10 \mu \mathrm{M}$ and CC50 of 390 $\mathrm{M}$. By both a time addition and an ATPase assays, the authors identified the post-entry steps action of Bananins, affecting de helicase function (Tanner et al., 2005).

\section{Different approaches for CoVs treatment}

As an alternative treatment, targeting host process during viral infection can play an important role (Sayce et al., 2010; Ullah et al., 2019). Nitazoxanide is a broad-spectrum antiviral agent used to treat viral infections (Rossignol, 2014; Jasenosky et al., 2019), being its activity related to the interference in host-regulated pathways important during viral replication (Rossignol, 2016). In vitro studies demonstrated that Nitazoxanide inhibited MERS-CoV in LLC-MK2 cells, as its derivate tizoxanide, with an EC50 of $0.92 \mu \mathrm{g} / \mathrm{mL}$ and $0.83 \mu \mathrm{g} / \mathrm{mL}$, respectively.

Another host-target compound is saracatinib, an inhibitor of tyrosine kinases (SFKs). It was described to suppress early stages of MERS-CoV replication cycle in Huh7 cells (EC50 of $2.9 \mu \mathrm{M}$ and CC50 > 50 $\mathrm{M}$ ), possibly by affecting the SFKs pathways (Shin et al., 2018). Also, Cyclosporin A (CsA) which is a peptide that has activity on hosts cyclophilin family enzymes (isomerases that act like as chaperones) (PubChem, 2005a; Davis et al., 2010), inhibited SARS-CoV, MERS-CoV and MHV in human and animals infected cell culture. CsA was considered as a broad-spectrum antiviral for CoVs and its activity seems to be related to genome replication/transcription steps in all CoVs infections (de Wilde et al., 2011, 2013; Pfefferle et al., 2011).

The interference RNA (iRNAs) are small noncoding RNAs associated with controlling the expression of genetic information (Wilson and Doudna, 2013), and has been described as promising candidate for the treatment of innumerous diseases, as virus infection (Y et al., 2007; Shah and Schaffer, 2011; Sanan-Mishra et al., 2017). The short interference RNAs (siRNAs) were described as an effective antiviral treatment for the Feline infectious peritonitis virus (FIPV), a type of Feline coronavirus (FCoV) in vitro (McDonagh et al., 2011, 2015). Li and colleagues designed and 
synthesized siRNAs that targeted the $\mathrm{M}$ and $\mathrm{N}$ genes of swine and porcine coronaviruses (SECoV and PDCoV, respectively). These siRNAs inhibited $99 \%$ of the expression of this proteins in both Vero and LLC-PK1 infected cells (Li et al., 2019). Moreover, synthetic siRNA on structural proteins E, M and $\mathrm{N}$ of SARS-CoV in Vero cells showed imperative reduction of the target genes expression (Shi et al., 2005). siRNAs targeting the structural proteins $7 \mathrm{a}, 7 \mathrm{~b}, 3 \mathrm{a}, 3 \mathrm{~b}$ and $\mathrm{S}$ reduced approximately $70 \%$ of SARS-CoV progeny in Vero cells (Åkerström et al., 2007).

\section{Potential candidate drugs for clinical trials against SARS-CoV-2}

The nucleoside analog Remdesivir (GS-5734) is a monophosphoramidate prodrug, which has antiviral activity described against Ebola virus (EBOV) in non-primate humans (Warren et al., 2016, 57). Its activity was assessed in human airways epithelial (HAE) cells infected with SARS-CoV (EC50 and CC50 of $0.069 \mu \mathrm{M}$ and $>10 \mu \mathrm{M}$, respectively) and MERS-CoV (EC50 and CC50 of $0.074 \mu \mathrm{M}$ and $>10 \mu \mathrm{M}$, respectively) and demonstrated to inhibit RdRp. Also, GS-5734 inhibited bat CoV in HAE cells. To confirm this results, GS-5734 were used in in vivo SARS-CoV model assay and demonstrated to reduce virus titers and SARS-CoV-induced lung pathologies (Sheahan et al., 2017). Furthermore, this compound reduced the severity of MERS-CoV disease, virus replication and damage in the lungs of rhesus macaque (Wit et al., 2020). GS-5734 is a possible candidate for clinical trials to treat SARS-CoV-2 patients, since inhibited SARS-CoV-2 replication in vitro (Wang et al., 2020).

Lopinavir is a protease inhibitor that demonstrated antiviral activities protecting the cells of MERS-CoV infection (EC50 of $8 \mu \mathrm{M}$ ) and reducing viral loads in animals assays (Wilde et al., 2014; Kim et al., 2015). These results are in disagreement with another work that was unable to demonstrate in vitro antiviral activity using lopinavir (Chan et al., 2013). In clinical assays for MERS-CoV, lopinavir reduced clinical outcomes and viral load in some cases (Sheahan et al., 2020; Yao et al., 2020a). To SARS-CoV, lopinavir had a low to medium antiviral activity in vitro, and in vivo assays has not been performed yet (Yao et al., 2020a). Lopinavir also played an important role in clinical outcome in SARS-CoV infected patients, so it could represent a possibility for the treatment of SARSCoV-2. The association with ritonavir and interferon could also improve the outcome results (Kim et al., 2015).

Choroquine is a 9-aminoquinole that increases the $\mathrm{pH}$ in acidic vesicles (Mauthe et al., 2018) and possess antiviral activities against HIV and other viruses (Jacobson et al., 2016; Al-Bari, 2017). Chloroquine was described as an entry inhibitor of SARS-CoV infection in Vero cells and prevented 
the spread of the virus (Vincent et al., 2005). Moreover, it affected the replication of FCoV in Felis catus cells and monocytes in entry and post-entry stages. And in vivo assays in cats demonstrated that chloroquine improved the clinical score of treated-groups when compared to the untreated-group (Takano et al., 2013). Chloroquine had its antiviral activities tested in Vero cells (EC50 of $5.47 \mu \mathrm{M}$ ) and demonstrated as good candidate for clinical trials for the treatment of SARS-CoV-2 (Wang et al., 2020; Yao et al., 2020b). However, chloroquine presents significant side effects that can interfere in its use in clinical treatment (Liu et al., 2020). Hydroxychloquine is an analogue of chloroquine which is less toxic and were described to have antiviral activity inhibiting SARS-CoV-2 in vitro with EC50 of $0.72 \mu \mathrm{M}$ (Liu et al., 2020; Yao et al., 2020b). In clinical trials, hydroxychloroquine reduced symptoms from SARS-CoV-2 patients, and the association with azithromycin, reinforced its effects (Gautret et al., 2020).

\section{PROSPECTIVES}

The aim of this review was to summarize data from literature about compounds that possess antiCoVs activity and could be candidates to the treatment of the already described for human and animal CoVs. All together, these studies demonstrate possible and already in course treatments for CoVs and elucidate novel approaches to handle SARS-CoV-2 patients.

Most of the drugs in use for CoVs infected individuals presents side effects as nauseas, headache, diarrhea, urticaria, pathologies related to gastrointestinal system and interference with liver enzymes (Ruiz-Irastorza et al., 2010; Takano et al., 2013; Roques et al., 2018; Yao et al., 2020a). Moreover, RNA viruses is known for having high level mutations (error rate) in transcription process by RdRps, sometimes resulting in evolution (Ganeshpurkar et al., 2019). This process also can produce resistance to antiviral treatment, as was seen in HIV, HCV and Influenza viruses (Laplante and St George, 2014; Li and Chung, 2019; Olearo et al., 2019; Takashita, 2020). So, the development of new treatment options is critical and efforts have focused on targeted therapies which aim to improve patient outcome by increasing antiviral activity associated with minimal toxicity.

Approaches as targeting host-immune factors or using iRNAs could be an alternative to treat viral infections. Also, the use of bioinformatics tools, as drug design, to predict and generate peptides directed to specific proteins in viral replication is a relevant approach to development of new drug treatment (Lengauer and Sing, 2006; Villegas-Rosales et al., 2012). In literature, there are several predicted drugs screened only in silico and in enzymatic and interaction assays (Chen et al., 2005; 
Kaeppler et al., 2005; Lee et al., 2005; Kim et al., 2012). Associated to these experiments, in vitro and in vivo assays are need to confirm its activities in biological models, and predict pharmacological outcomes (Toxicology, 2007). So, here we aimed to describe compounds that were at least tested in in vitro models. Therefore, would be desirable that these compounds were also tested in vivo to elucidate the role of these compounds in pathogenesis and viral load of CoVs, as well to evaluate the side effects. The lack of in vivo assays may represent a delay in anti-CoVs drug development, which could impact directly in SARS-CoV-2 pandemic treatment.

Moreover, here we described compounds that had antiviral activity for human and animal CoVs. As we know, most of the human CoVs emerged from zoonotic transmission from bat, porcine, dromedaries and civet cats (Huynh et al., 2012; Coleman and Frieman, 2014; Reusken et al., 2016), and Coronaviridae seems to have very well conserved genome and structures between theirs viruses (Huentelman Matthew J. et al., 2004; Guan et al., 2012; Yang and Leibowitz, 2015; Madhugiri et al., 2018). Therefore, we propose that compounds which had antiviral activity in different CoVs (broadspectrum activity), human and/or animal, could provide potential candidates for the SARS-CoV-2 treatment.

\section{CONCLUSIONS}

The spread of SARS-CoV-2 worldwide is classified as a pandemic disease and represent a threat to global public health. By 15 April 2020, SARS-CoV-2 infected 1914916 people and caused 123010 deaths around the world (WHO, 2020). In this context, compounds already described with antiviral against human and animal coronaviruses could be an alternative for developing new SARSCoV-2 treatments. The reduction of COVID-19 outcomes can be considered a leading challenged to worldwide health public system. 
Conflicts of Interest: The authors declare no conflict of interest.

\section{Author Contributions}

IA: Drafting the manuscript and literature review. VR: Drafting the manuscript and illustration. AC and RS: critical revision and editing, and final approval of the final version. All the authors read and approved the final manuscript.

\section{Acknowledgements}

Not applicable.

\section{Funding}

The authors received financial support from the Royal Society - Newton Advanced Fellowship (grant reference NA 150195) and FAPEMIG (Minas Gerais Research Foundation - SICONV 793988/2013; APQ-02872-16 and APQ-03385-18). ACGJ received productivity fellowship (311219/2019-5) from the CNPq (National Counsel of Technological and Scientific Development). The Brazilian funding agencies CNPq, CAPES (Coordination for the Improvement of Higher Education), and FAPEMIG provide financial support to the National Institute of Science and Technology in Theranostics and Nanobiotechnology - INCT-Teranano (CNPq-465669/2014-0). Sabino-Silva, R received a fellowship from PrInt CAPES/UFU. 


\section{Antivirals against human-animal Coronaviruses}

\section{REFERENCES}

Adedeji, A. O., Severson, W., Jonsson, C., Singh, K., Weiss, S. R., and Sarafianos, S. G. (2013). Novel Inhibitors of Severe Acute Respiratory Syndrome Coronavirus Entry That Act by Three Distinct Mechanisms. J. Virol. 87, 8017-8028. doi:10.1128/JVI.00998-13.

Åkerström, S., Mirazimi, A., and Tan, Y.-J. (2007). Inhibition of SARS-CoV replication cycle by small interference RNAs silencing specific SARS proteins, 7a/7b, 3a/3b and S. Antiviral Res. 73, 219-227. doi:10.1016/j.antiviral.2006.10.008.

Al-Bari, Md. A. A. (2017). Targeting endosomal acidification by chloroquine analogs as a promising strategy for the treatment of emerging viral diseases. Pharmacol. Res. Perspect., e00293. doi:10.1002/prp2.293@ 10.1002/(ISSN)2052-1707.ASIARESEARCH.

Al-Tawfiq, J. A., Momattin, H., Dib, J., and Memish, Z. A. (2014). Ribavirin and interferon therapy in patients infected with the Middle East respiratory syndrome coronavirus: an observational study. Int. J. Infect. Dis. 20, 42-46. doi:10.1016/j.ijid.2013.12.003.

Anand, K., Ziebuhr, J., Wadhwani, P., Mesters, J. R., and Hilgenfeld, R. (2003). Coronavirus Main Proteinase (3CLpro) Structure: Basis for Design of Anti-SARS Drugs. Science 300, 17631767. doi:10.1126/science.1085658.

Andersen, K. G., Rambaut, A., Lipkin, W. I., Holmes, E. C., and Garry, R. F. (2020). The proximal origin of SARS-CoV-2. Nat. Med., 1-3. doi:10.1038/s41591-020-0820-9.

Barnard, D. L., Day, C. W., Bailey, K., Heiner, M., Montgomery, R., Lauridsen, L., et al. (2006). Enhancement of the infectivity of SARS-CoV in BALB/c mice by IMP dehydrogenase inhibitors, including ribavirin. Antiviral Res. 71, 53-63. doi:10.1016/j.antiviral.2006.03.001.

Barnard, D. L., Hubbard, V. D., Burton, J., Smee, D. F., Morrey, J. D., Otto, M. J., et al. (2004). Inhibition of severe acute respiratory syndrome-associated coronavirus (SARSCoV) by calpain inhibitors and beta-D-N4-hydroxycytidine. Antivir. Chem. Chemother. 15, 15-22. doi:10.1177/095632020401500102.

Belouzard, S., Chu, V. C., and Whittaker, G. R. (2009). Activation of the SARS coronavirus spike protein via sequential proteolytic cleavage at two distinct sites. Proc. Natl. Acad. Sci. U. S. A. 106, 5871-5876. doi:10.1073/pnas.0809524106.

Cao, Y., Li, L., Feng, Z., Wan, S., Huang, P., Sun, X., et al. (2020). Comparative genetic analysis of the novel coronavirus (2019-nCoV/SARS-CoV-2) receptor ACE2 in different populations. Cell Discov. 6, 11. doi:10.1038/s41421-020-0147-1.

CDC (2020). Coronavirus | Human Coronavirus Types | CDC. Available at: https://www.cdc.gov/coronavirus/types.html [Accessed March 31, 2020].

Ceccarelli, M., Berretta, M., Rullo, E. V., Nunnari, G., and Cacopardo, B. (2020). Differences and similarities between Severe Acute Respiratory Syndrome (SARS)-CoronaVirus (CoV) and SARS-CoV-2. Would a rose by another name smell as sweet? 3. 
Chan, J. F. W., Chan, K.-H., Kao, R. Y. T., To, K. K. W., Zheng, B.-J., Li, C. P. Y., et al. (2013). Broad-spectrum antivirals for the emerging Middle East respiratory syndrome coronavirus. $J$. Infect. 67, 606-616. doi:10.1016/j.jinf.2013.09.029.

Chen, L.-R., Wang, Y.-C., Lin, Y. W., Chou, S.-Y., Chen, S.-F., Liu, L. T., et al. (2005). Synthesis and evaluation of isatin derivatives as effective SARS coronavirus 3CL protease inhibitors. Bioorg. Med. Chem. Lett. 15, 3058-3062. doi:10.1016/j.bmcl.2005.04.027.

Cinatl, J., Morgenstern, B., Bauer, G., Chandra, P., Rabenau, H., and Doerr, H. W. (2003). Glycyrrhizin, an active component of liquorice roots, and replication of SARS-associated coronavirus. The Lancet 361, 2045-2046. doi:10.1016/S0140-6736(03)13615-X.

Coleman, C. M., and Frieman, M. B. (2014). Coronaviruses: Important Emerging Human Pathogens. J. Virol. 88, 5209-5212. doi:10.1128/JVI.03488-13.

Cui, J., Li, F., and Shi, Z.-L. (2019). Origin and evolution of pathogenic coronaviruses. Nat. Rev. Microbiol. 17, 181-192. doi:10.1038/s41579-018-0118-9.

Dai, C., Ma, Y., Zhao, Z., Zhao, R., Wang, Q., Wu, Y., et al. (2008). Mucroporin, the First Cationic Host Defense Peptide from the Venom of Lychas mucronatus. Antimicrob. Agents Chemother. 52, 3967-3972. doi:10.1128/AAC.00542-08.

Davis, T. L., Walker, J. R., Campagna-Slater, V., Finerty, P. J., Paramanathan, R., Bernstein, G., et al. (2010). Structural and biochemical characterization of the human cyclophilin family of peptidyl-prolyl isomerases. PLoS Biol. 8, e1000439. doi:10.1371/journal.pbio.1000439.

Day, C. W., Baric, R., Cai, S. X., Frieman, M., Kumaki, Y., Morrey, J. D., et al. (2009). A new mouseadapted strain of SARS-CoV as a lethal model for evaluating antiviral agents in vitro and in vivo. Virology 395, 210-222. doi:10.1016/j.virol.2009.09.023.

de Wilde, A. H., Raj, V. S., Oudshoorn, D., Bestebroer, T. M., van Nieuwkoop, S., Limpens, R. W. A. L., et al. (2013). MERS-coronavirus replication induces severe in vitro cytopathology and is strongly inhibited by cyclosporin A or interferon- $\alpha$ treatment. J. Gen. Virol. 94, 1749-1760. doi:10.1099/vir.0.052910-0.

de Wilde, A. H., Zevenhoven-Dobbe, J. C., van der Meer, Y., Thiel, V., Narayanan, K., Makino, S., et al. (2011). Cyclosporin A inhibits the replication of diverse coronaviruses. J. Gen. Virol. 92, 2542-2548. doi:10.1099/vir.0.034983-0.

Duffy, S. (2018). Why are RNA virus mutation rates so damn high? PLOS Biol. 16, e3000003. doi:10.1371/journal.pbio.3000003.

Fehr, A. R., and Perlman, S. (2015). Coronaviruses: An Overview of Their Replication and Pathogenesis. Methods Mol. Biol. Clifton NJ 1282, 1-23. doi:10.1007/978-1-4939-2438-7_1.

Gan, Y.-R., Huang, H., Huang, Y.-D., Rao, C.-M., Zhao, Y., Liu, J.-S., et al. (2006). Synthesis and activity of an octapeptide inhibitor designed for SARS coronavirus main proteinase. Peptides 27, 622-625. doi:10.1016/j.peptides.2005.09.006. 
Ganeshpurkar, A., Gutti, G., and Singh, S. K. (2019). “Chapter 1 - RNA-Dependent RNA Polymerases and Their Emerging Roles in Antiviral Therapy," in Viral Polymerases, ed. S. P. Gupta (Academic Press), 1-42. doi:10.1016/B978-0-12-815422-9.00001-2.

Gautret, P., Lagier, J.-C., Parola, P., Hoang, V. T., Meddeb, L., Mailhe, M., et al. (2020). Hydroxychloroquine and azithromycin as a treatment of COVID-19: results of an open-label non-randomized clinical trial. Int. J. Antimicrob. Agents, 105949. doi:10.1016/j.ijantimicag.2020.105949.

Gorbalenya, A. E., Baker, S. C., Baric, R. S., de Groot, R. J., Drosten, C., Gulyaeva, A. A., et al. (2020a). Severe acute respiratory syndrome-related coronavirus : The species and its viruses a statement of the Coronavirus Study Group. Microbiology doi:10.1101/2020.02.07.937862.

Gorbalenya, A. E., Baker, S. C., Baric, R. S., de Groot, R. J., Drosten, C., Gulyaeva, A. A., et al. (2020b). The species Severe acute respiratory syndrome-related coronavirus : classifying 2019nCoV and naming it SARS-CoV-2. Nat. Microbiol. 5, 536-544. doi:10.1038/s41564-0200695-z.

Graham, R. L., Donaldson, E. F., and Baric, R. S. (2013). A decade after SARS: strategies for controlling emerging coronaviruses. Nat. Rev. Microbiol. 11, 836-848. doi: $10.1038 /$ nrmicro3143.

Guan, B.-J., Su, Y.-P., Wu, H.-Y., and Brian, D. A. (2012). Genetic Evidence of a Long-Range RNARNA Interaction between the Genomic 5' Untranslated Region and the Nonstructural Protein 1 Coding Region in Murine and Bovine Coronaviruses. J. Virol. 86, 4631-4643. doi:10.1128/JVI.06265-11.

Haga, S., Nagata, N., Okamura, T., Yamamoto, N., Sata, T., Yamamoto, N., et al. (2010). TACE antagonists blocking ACE2 shedding caused by the spike protein of SARS-CoV are candidate antiviral compounds. Antiviral Res. 85, 551-555. doi:10.1016/j.antiviral.2009.12.001.

Haga, S., Yamamoto, N., Nakai-Murakami, C., Osawa, Y., Tokunaga, K., Sata, T., et al. (2008). Modulation of TNF- -converting enzyme by the spike protein of SARS-CoV and ACE2 induces TNF- production and facilitates viral entry. Proc. Natl. Acad. Sci. 105, 7809-7814. doi:10.1073/pnas.0711241105.

Ho, T.-Y., Wu, S.-L., Chen, J.-C., Li, C.-C., and Hsiang, C.-Y. (2007). Emodin blocks the SARS coronavirus spike protein and angiotensin-converting enzyme 2 interaction. Antiviral Res. 74, 92-101. doi:10.1016/j.antiviral.2006.04.014.

Hoever, G., Baltina, L., Michaelis, M., Kondratenko, R., Baltina, L., Tolstikov, G. A., et al. (2005). Antiviral Activity of Glycyrrhizic Acid Derivatives against SARS-Coronavirus. J. Med. Chem. 48, 1256-1259. doi:10.1021/jm0493008.

Hoffmann, M., Kleine-Weber, H., Schroeder, S., Krüger, N., Herrler, T., Erichsen, S., et al. (2020). SARS-CoV-2 Cell Entry Depends on ACE2 and TMPRSS2 and Is Blocked by a Clinically Proven Protease Inhibitor. Cell, S0092867420302294. doi:10.1016/j.cell.2020.02.052.

Huentelman Matthew J., Zubcevic Jasenka, Hernández Prada Jose A., Xiao Xiaodong, Dimitrov Dimiter S., Raizada Mohan K., et al. (2004). Structure-Based Discovery of a Novel 


\section{Antivirals against human-animal Coronaviruses}

Angiotensin-Converting Enzyme 2 Inhibitor. Hypertension 44, 903-906. doi:10.1161/01.HYP.0000146120.29648.36.

Huynh, J., Li, S., Yount, B., Smith, A., Sturges, L., Olsen, J. C., et al. (2012). Evidence Supporting a Zoonotic Origin of Human Coronavirus Strain NL63. J. Virol. 86, 12816-12825. doi:10.1128/JVI.00906-12.

Jacobson, J. M., Bosinger, S. E., Kang, M., Belaunzaran-Zamudio, P., Matining, R. M., Wilson, C. C., et al. (2016). The Effect of Chloroquine on Immune Activation and Interferon Signatures Associated with HIV-1. AIDS Res. Hum. Retroviruses 32, 636-647. doi:10.1089/aid.2015.0336.

Jasenosky, L. D., Cadena, C., Mire, C. E., Borisevich, V., Haridas, V., Ranjbar, S., et al. (2019). The FDA-Approved Oral Drug Nitazoxanide Amplifies Host Antiviral Responses and Inhibits Ebola Virus. iScience 19, 1279-1290. doi:10.1016/j.isci.2019.07.003.

Kaeppler, U., Stiefl, N., Schiller, M., Vicik, R., Breuning, A., Schmitz, W., et al. (2005). A New Lead for Nonpeptidic Active-Site-Directed Inhibitors of the Severe Acute Respiratory Syndrome Coronavirus Main Protease Discovered by a Combination of Screening and Docking Methods. J. Med. Chem. 48, 6832-6842. doi:10.1021/jm0501782.

Kahn, J. S., and McIntosh, K. (2005). History and Recent Advances in Coronavirus Discovery. Pediatr. Infect. Dis. J. 24, S223. doi:10.1097/01.inf.0000188166.17324.60.

Katz, M. (1977). Anthelmintics. Drugs 13, 124-136. doi:10.2165/00003495-197713020-00002.

Kesel, A. J. (2003). A system of protein target sequences for anti-RNA-viral chemotherapy by a vitamin B6-Derived zinc-Chelating trioxa-adamantane-triol. Bioorg. Med. Chem. 11, 45994613. doi:10.1016/S0968-0896(03)00500-5.

Kim, D., Lee, J.-Y., Yang, J.-S., Kim, J. W., Kim, V. N., and Chang, H. (2020). The architecture of SARS-CoV-2 transcriptome. bioRxiv, 2020.03.12.988865. doi:10.1101/2020.03.12.988865.

Kim, U. J., Won, E.-J., Kee, S.-J., Jung, S.-I., and Jang, H.-C. (2015). Combination therapy with lopinavir/ritonavir, ribavirin and interferon-alpha for Middle East respiratory syndrome: a case report. Antivir. Ther. 21, 455-459. doi:10.3851/IMP3002.

Kim, Y., Lovell, S., Tiew, K.-C., Mandadapu, S. R., Alliston, K. R., Battaile, K. P., et al. (2012). BroadSpectrum Antivirals against 3C or 3C-Like Proteases of Picornaviruses, Noroviruses, and Coronaviruses. J. Virol. 86, 11754-11762. doi:10.1128/JVI.01348-12.

Kipar, A., Meli, M. L., Baptiste, K. E., Bowker, L. J., and Lutz, H. (2010). Sites of feline coronavirus persistence in healthy cats. J. Gen. Virol. 91, 1698-1707. doi:10.1099/vir.0.020214-0.

Lai, C.-C., Shih, T.-P., Ko, W.-C., Tang, H.-J., and Hsueh, P.-R. (2020). Severe acute respiratory syndrome coronavirus 2 (SARS-CoV-2) and coronavirus disease-2019 (COVID-19): The epidemic and the challenges. Int. J. Antimicrob. Agents 55, 105924. doi:10.1016/j.ijantimicag.2020.105924. 


\section{Antivirals against human-animal Coronaviruses}

Lai, M. M., and Stohlman, S. A. (1981). Comparative analysis of RNA genomes of mouse hepatitis viruses. $\quad$ J. Virol. 38, 661-670. Available at: https://www.ncbi.nlm.nih.gov/pmc/articles/PMC171196/ [Accessed March 31, 2020].

Laplante, J., and St George, K. (2014). Antiviral resistance in influenza viruses: laboratory testing. Clin. Lab. Med. 34, 387-408. doi:10.1016/j.cll.2014.02.010.

Lee, T.-W., Cherney, M. M., Huitema, C., Liu, J., James, K. E., Powers, J. C., et al. (2005). Crystal Structures of the Main Peptidase from the SARS Coronavirus Inhibited by a Substrate-like Azapeptide Epoxide. J. Mol. Biol. 353, 1137-1151. doi:10.1016/j.jmb.2005.09.004.

Lengauer, T., and Sing, T. (2006). Bioinformatics-assisted anti-HIV therapy. Nat. Rev. Microbiol. 4, 790-797. doi:10.1038/nrmicro1477.

Li, D. K., and Chung, R. T. (2019). Overview of Direct-Acting Antiviral Drugs and Drug Resistance of Hepatitis C Virus. Methods Mol. Biol. Clifton NJ 1911, 3-32. doi:10.1007/978-1-4939-8976$8 \_1$.

Li, K., Li, H., Bi, Z., Song, D., Zhang, F., Lei, D., et al. (2019). Significant inhibition of re-emerged and emerging swine enteric coronavirus in vitro using the multiple shRNA expression vector. Antiviral Res. 166, 11-18. doi:10.1016/j.antiviral.2019.03.010.

Li, Q., Zhao, Z., Zhou, D., Chen, Y., Hong, W., Cao, L., et al. (2011). Virucidal activity of a scorpion venom peptide variant mucroporin-M1 against measles, SARS-CoV and influenza H5N1 viruses. Peptides 32, 1518-1525. doi:10.1016/j.peptides.2011.05.015.

Lipinski, C. A., Lombardo, F., Dominy, B. W., and Feeney, P. J. (2001). Experimental and computational approaches to estimate solubility and permeability in drug discovery and development settings. Adv. Drug Deliv. Rev. 46, 3-26. doi:10.1016/s0169-409x(00)00129-0.

Liu, J., Cao, R., Xu, M., Wang, X., Zhang, H., Hu, H., et al. (2020). Hydroxychloroquine, a less toxic derivative of chloroquine, is effective in inhibiting SARS-CoV-2 infection in vitro. Cell Discov. 6, 1-4. doi:10.1038/s41421-020-0156-0.

Lu, G., Wang, Q., and Gao, G. F. (2015). Bat-to-human: spike features determining 'host jump' of coronaviruses SARS-CoV, MERS-CoV, and beyond. Trends Microbiol. 23, 468-478. doi:10.1016/j.tim.2015.06.003.

Lusvarghi, S., and Bewley, C. A. (2016). Griffithsin: An Antiviral Lectin with Outstanding Therapeutic Potential. Viruses 8. doi:10.3390/v8100296.

Madhugiri, R., Karl, N., Petersen, D., Lamkiewicz, K., Fricke, M., Wend, U., et al. (2018). Structural and functional conservation of cis-acting RNA elements in coronavirus 5'-terminal genome regions. Virology 517, 44-55. doi:10.1016/j.virol.2017.11.025.

Matsuyama, S., Nao, N., Shirato, K., Kawase, M., Saito, S., Takayama, I., et al. (2020). Enhanced isolation of SARS-CoV-2 by TMPRSS2-expressing cells. Proc. Natl. Acad. Sci. doi:10.1073/pnas.2002589117. 
Mauthe, M., Orhon, I., Rocchi, C., Zhou, X., Luhr, M., Hijlkema, K.-J., et al. (2018). Chloroquine inhibits autophagic flux by decreasing autophagosome-lysosome fusion. Autophagy 14, 14351455. doi:10.1080/15548627.2018.1474314.

McDonagh, P., Sheehy, P. A., and Norris, J. M. (2011). In vitro inhibition of feline coronavirus replication by small interfering RNAs. Vet. Microbiol. 150, 220-229. doi:10.1016/j.vetmic.2011.01.023.

McDonagh, P., Sheehy, P. A., and Norris, J. M. (2015). Combination siRNA therapy against feline coronavirus can delay the emergence of antiviral resistance in vitro. Vet. Microbiol. 176, 1018. doi:10.1016/j.vetmic.2014.12.009.

Millet, J. K., Séron, K., Labitt, R. N., Danneels, A., Palmer, K. E., Whittaker, G. R., et al. (2016). Middle East respiratory syndrome coronavirus infection is inhibited by griffithsin. Antiviral Res. 133, 1-8. doi:10.1016/j.antiviral.2016.07.011.

Murphy, F., and Middleton, M. (2012). “45 - Cytostatic and cytotoxic drugs,” in Side Effects of Drugs Annual A worldwide yearly survey of new data in adverse drug reactions and interactions., ed. J. K. Aronson (Elsevier), 731-747. doi:10.1016/B978-0-444-59499-0.00045-3.

O’Keefe, B. R., Giomarelli, B., Barnard, D. L., Shenoy, S. R., Chan, P. K. S., McMahon, J. B., et al. (2010). Broad-Spectrum In Vitro Activity and In Vivo Efficacy of the Antiviral Protein Griffithsin against Emerging Viruses of the Family Coronaviridae. J. Virol. 84, 2511-2521. doi:10.1128/JVI.02322-09.

Olearo, F., Nguyen, H., Bonnet, F., Yerly, S., Wandeler, G., Stoeckle, M., et al. (2019). Impact of the M184V/I Mutation on the Efficacy of Abacavir/Lamivudine/Dolutegravir Therapy in HIV Treatment-Experienced Patients. Open Forum Infect. Dis. 6, ofz330. doi:10.1093/ofid/ofz330.

Payne, S. (2017). "Chapter 17 - Family Coronaviridae," in Viruses, ed. S. Payne (Academic Press), 149-158. doi:10.1016/B978-0-12-803109-4.00017-9.

Peters, H. L., Jochmans, D., de Wilde, A. H., Posthuma, C. C., Snijder, E. J., Neyts, J., et al. (2015). Design, synthesis and evaluation of a series of acyclic fleximer nucleoside analogues with anticoronavirus activity. Bioorg. Med. Chem. Lett. 25, 2923-2926. doi:10.1016/j.bmcl.2015.05.039.

Pfefferle, S., Schöpf, J., Kögl, M., Friedel, C. C., Müller, M. A., Carbajo-Lozoya, J., et al. (2011). The SARS-Coronavirus-Host Interactome: Identification of Cyclophilins as Target for PanCoronavirus Inhibitors. PLoS Pathog. 7. doi:10.1371/journal.ppat.1002331.

Prabakaran, P., Xiao, X., and Dimitrov, D. S. (2004). A model of the ACE2 structure and function as a SARS-CoV receptor. Biochem. Biophys. Res. Commun. 314, 235-241. doi:10.1016/j.bbrc.2003.12.081.

PubChem (2005a). Cyclosporin A. Available https://pubchem.ncbi.nlm.nih.gov/compound/5284373 [Accessed April 1, 2020].

PubChem (2005b). Mycophenolic acid. Available at: https://pubchem.ncbi.nlm.nih.gov/compound/446541 [Accessed April 1, 2020]. 


\section{Antivirals against human-animal Coronaviruses}

PubChem (2005c). Ribavirin. Available at: https://pubchem.ncbi.nlm.nih.gov/compound/37542 [Accessed April 1, 2020].

Pyrc, K., Bosch, B. J., Berkhout, B., Jebbink, M. F., Dijkman, R., Rottier, P., et al. (2006). Inhibition of human coronavirus NL63 infection at early stages of the replication cycle. Antimicrob. Agents Chemother. 50, 2000-2008. doi:10.1128/AAC.01598-05.

Ramajayam, R., Tan, K.-P., Liu, H.-G., and Liang, P.-H. (2010). Synthesis, docking studies, and evaluation of pyrimidines as inhibitors of SARS-CoV 3CL protease. Bioorg. Med. Chem. Lett. 20, 3569-3572. doi:10.1016/j.bmcl.2010.04.118.

Ramos-Tovar, E., and Muriel, P. (2019). "Chapter 9 - Phytotherapy for the Liver*," in Dietary Interventions in Liver Disease, eds. R. R. Watson and V. R. Preedy (Academic Press), 101121. doi:10.1016/B978-0-12-814466-4.00009-4.

Reusken, C. B., Raj, V. S., Koopmans, M. P., and Haagmans, B. L. (2016). Cross host transmission in the emergence of MERS coronavirus. Curr. Opin. Virol. 16, 55-62. doi:10.1016/j.coviro.2016.01.004.

Roques, P., Thiberville, S.-D., Dupuis-Maguiraga, L., Lum, F.-M., Labadie, K., Martinon, F., et al. (2018). Paradoxical Effect of Chloroquine Treatment in Enhancing Chikungunya Virus Infection. Viruses 10. doi:10.3390/v10050268.

Rossignol, J.-F. (2014). Nitazoxanide: A first-in-class broad-spectrum antiviral agent. Antiviral Res. 110, 94-103. doi:10.1016/j.antiviral.2014.07.014.

Rossignol, J.-F. (2016). Nitazoxanide, a new drug candidate for the treatment of Middle East respiratory syndrome coronavirus. J. Infect. Public Health 9, 227-230. doi:10.1016/j.jiph.2016.04.001.

Ruiz-Irastorza, G., Ramos-Casals, M., Brito-Zeron, P., and Khamashta, M. A. (2010). Clinical efficacy and side effects of antimalarials in systemic lupus erythematosus: a systematic review. Ann. Rheum. Dis. 69, 20-28. doi:10.1136/ard.2008.101766.

Saijo, M., Morikawa, S., Fukushi, S., Mizutani, T., Hasegawa, H., Nagata, N., et al. (2005). Inhibitory effect of mizoribine and ribavirin on the replication of severe acute respiratory syndrome (SARS)-associated coronavirus. Antiviral Res. 66, 159-163. doi:10.1016/j.antiviral.2005.01.003.

Sanan-Mishra, N., Chakraborty, S., Gupta, D., and Mukherjee, S. K. (2017). "RNAi Suppressors: Biology and Mechanisms," in Plant Epigenetics RNA Technologies., eds. N. Rajewsky, S. Jurga, and J. Barciszewski (Cham: Springer International Publishing), 199-230. doi:10.1007/978-3-319-55520-1_11.

Sayce, A. C., Miller, J. L., and Zitzmann, N. (2010). Targeting a host process as an antiviral approach against dengue virus. Trends Microbiol. 18, 323-330. doi:10.1016/j.tim.2010.04.003.

Schwarz, S., Wang, K., Yu, W., Sun, B., and Schwarz, W. (2011). Emodin inhibits current through SARS-associated coronavirus $3 \mathrm{a}$ protein. Antiviral Res. 90, 64-69. doi:10.1016/j.antiviral.2011.02.008. 
Shah, P. P., Wang, T., Kaletsky, R. L., Myers, M. C., Purvis, J. E., Jing, H., et al. (2010). A SmallMolecule Oxocarbazate Inhibitor of Human Cathepsin L Blocks Severe Acute Respiratory Syndrome and Ebola Pseudotype Virus Infection into Human Embryonic Kidney 293T cells. Mol. Pharmacol. 78, 319-324. doi:10.1124/mol.110.064261.

Shah, P. S., and Schaffer, D. V. (2011). Antiviral RNAi: Translating Science Towards Therapeutic Success. Pharm. Res. 28, 2966-2982. doi:10.1007/s11095-011-0549-8.

Sheahan, T. P., Sims, A. C., Graham, R. L., Menachery, V. D., Gralinski, L. E., Case, J. B., et al. (2017). Broad-spectrum antiviral GS-5734 inhibits both epidemic and zoonotic coronaviruses. Sci. Transl. Med. 9. doi:10.1126/scitranslmed.aal3653.

Sheahan, T. P., Sims, A. C., Leist, S. R., Schäfer, A., Won, J., Brown, A. J., et al. (2020). Comparative therapeutic efficacy of remdesivir and combination lopinavir, ritonavir, and interferon beta against MERS-CoV. Nat. Commun. 11, 1-14. doi:10.1038/s41467-019-13940-6.

Shi, Y., Yang, D. H., Xiong, J., Jia, J., Huang, B., and Jin, Y. X. (2005). Inhibition of genes expression of SARS coronavirus by synthetic small interfering RNAs. Cell Res. 15, 193-200. doi:10.1038/sj.cr.7290286.

Shie, J.-J., Fang, J.-M., Kuo, T.-H., Kuo, C.-J., Liang, P.-H., Huang, H.-J., et al. (2005). Inhibition of the severe acute respiratory syndrome $3 \mathrm{CL}$ protease by peptidomimetic $\alpha, \beta$-unsaturated esters. Bioorg. Med. Chem. 13, 5240-5252. doi:10.1016/j.bmc.2005.05.065.

Shin, J. S., Jung, E., Kim, M., Baric, R. S., and Go, Y. Y. (2018). Saracatinib Inhibits Middle East Respiratory Syndrome-Coronavirus Replication In Vitro. Viruses 10, 283. doi:10.3390/v10060283.

Siu, Y. L., Teoh, K. T., Lo, J., Chan, C. M., Kien, F., Escriou, N., et al. (2008). The M, E, and N structural proteins of the severe acute respiratory syndrome coronavirus are required for efficient assembly, trafficking, and release of virus-like particles. J. Virol. 82, 11318-11330. doi:10.1128/JVI.01052-08.

Struck, A.-W., Axmann, M., Pfefferle, S., Drosten, C., and Meyer, B. (2012). A hexapeptide of the receptor-binding domain of SARS corona virus spike protein blocks viral entry into host cells via the human receptor ACE2. Antiviral Res. 94, 288-296. doi:10.1016/j.antiviral.2011.12.012.

Sun, C., Chen, L., Yang, J., Luo, C., Zhang, Y., Li, J., et al. (2020). SARS-CoV-2 and SARS-CoV Spike-RBD Structure and Receptor Binding Comparison and Potential Implications on Neutralizing Antibody and Vaccine Development. bioRxiv, 2020.02.16.951723. doi:10.1101/2020.02.16.951723.

Tai, W., He, L., Zhang, X., Pu, J., Voronin, D., Jiang, S., et al. (2020). Characterization of the receptorbinding domain (RBD) of 2019 novel coronavirus: implication for development of RBD protein as a viral attachment inhibitor and vaccine. Cell. Mol. Immunol., 1-8. doi:10.1038/s41423-0200400-4.

Takano, T., Katoh, Y., Doki, T., and Hohdatsu, T. (2013). Effect of chloroquine on feline infectious peritonitis virus infection in vitro and in vivo. Antiviral Res. 99, 100-107. doi:10.1016/j.antiviral.2013.04.016. 
Takashita, E. (2020). Influenza Polymerase Inhibitors: Mechanisms of Action and Resistance. Cold Spring Harb. Perspect. Med. doi:10.1101/cshperspect.a038687.

Tanner, J. A., Zheng, B.-J., Zhou, J., Watt, R. M., Jiang, J.-Q., Wong, K.-L., et al. (2005). The Adamantane-Derived Bananins Are Potent Inhibitors of the Helicase Activities and Replication of SARS Coronavirus. Chem. Biol. 12, 303-311. doi:10.1016/j.chembiol.2005.01.006.

Toxicology, N. R. C. (US) C. on A. of T. T. to P. (2007). Application to the Study of Mechanisms of Action. National Academies Press (US) Available at: https://www.ncbi.nlm.nih.gov/books/NBK10203/ [Accessed December 28, 2019].

Ullah, H., Hou, W., Dakshanamurthy, S., and Tang, Q. (2019). Host targeted antiviral (HTA): functional inhibitor compounds of scaffold protein RACK1 inhibit herpes simplex virus proliferation. Oncotarget 10, 3209-3226. doi:10.18632/oncotarget.26907.

van Doremalen, N., Bushmaker, T., Morris, D. H., Holbrook, M. G., Gamble, A., Williamson, B. N., et al. (2020). Aerosol and Surface Stability of SARS-CoV-2 as Compared with SARS-CoV-1. N. Engl. J. Med. 0, null. doi:10.1056/NEJMc2004973.

Villegas-Rosales, P. M., Méndez-Tenorio, A., Ortega-Soto, E., and Barrón, B. L. (2012). Bioinformatics prediction of siRNAs as potential antiviral agents against dengue viruses. Bioinformation 8, 519-522. doi:10.6026/97320630008519.

Vincent, M. J., Bergeron, E., Benjannet, S., Erickson, B. R., Rollin, P. E., Ksiazek, T. G., et al. (2005). Chloroquine is a potent inhibitor of SARS coronavirus infection and spread. Virol. J. 2, 69. doi:10.1186/1743-422X-2-69.

Wang, M., Cao, R., Zhang, L., Yang, X., Liu, J., Xu, M., et al. (2020). Remdesivir and chloroquine effectively inhibit the recently emerged novel coronavirus (2019-nCoV) in vitro. Cell Res. 30, 269-271. doi:10.1038/s41422-020-0282-0.

Wang, Y., Sun, Y., Wu, A., Xu, S., Pan, R., Zeng, C., et al. (2015). Coronavirus nsp10/nsp16 Methyltransferase Can Be Targeted by nsp10-Derived Peptide In Vitro and In Vivo To Reduce Replication and Pathogenesis. J. Virol. 89, 8416-8427. doi:10.1128/JVI.00948-15.

Warren, T. K., Jordan, R., Lo, M. K., Ray, A. S., Mackman, R. L., Soloveva, V., et al. (2016). Therapeutic efficacy of the small molecule GS-5734 against Ebola virus in rhesus monkeys. Nature 531, 381-385. doi:10.1038/nature17180.

Weiss, S. R., and Navas-Martin, S. (2005). Coronavirus Pathogenesis and the Emerging Pathogen Severe Acute Respiratory Syndrome Coronavirus. Microbiol. Mol. Biol. Rev. 69, 635-664. doi:10.1128/MMBR.69.4.635-664.2005.

WHO (2020). Novel Coronavirus (2019-nCoV) situation reports. Available at: https://www.who.int/emergencies/diseases/novel-coronavirus-2019/situation-reports [Accessed April 15, 2020].

Wilde, A. H. de, Jochmans, D., Posthuma, C. C., Zevenhoven-Dobbe, J. C., Nieuwkoop, S. van, Bestebroer, T. M., et al. (2014). Screening of an FDA-Approved Compound Library Identifies 
Four Small-Molecule Inhibitors of Middle East Respiratory Syndrome Coronavirus Replication in Cell Culture. Antimicrob. Agents Chemother. 58, 4875-4884. doi:10.1128/AAC.03011-14.

Wilson, R. C., and Doudna, J. A. (2013). Molecular Mechanisms of RNA Interference. Annu. Rev. Biophys. 42, 217-239. doi:10.1146/annurev-biophys-083012-130404.

Wit, E. de, Feldmann, F., Cronin, J., Jordan, R., Okumura, A., Thomas, T., et al. (2020). Prophylactic and therapeutic remdesivir (GS-5734) treatment in the rhesus macaque model of MERS-CoV infection. Proc. Natl. Acad. Sci. 117, 6771-6776. doi:10.1073/pnas.1922083117.

Wrapp, D., Wang, N., Corbett, K. S., Goldsmith, J. A., Hsieh, C.-L., Abiona, O., et al. (2020). CryoEM Structure of the 2019-nCoV Spike in the Prefusion Conformation. bioRxiv, 2020.02.11.944462. doi:10.1101/2020.02.11.944462.

Wu, C.-J., Jan, J.-T., Chen, C.-M., Hsieh, H.-P., Hwang, D.-R., Liu, H.-W., et al. (2004). Inhibition of Severe Acute Respiratory Syndrome Coronavirus Replication by Niclosamide. Antimicrob. Agents Chemother. 48, 2693-2696. doi:10.1128/AAC.48.7.2693-2696.2004.

Wu, D., Wu, T., Liu, Q., and Yang, Z. (2020). The SARS-CoV-2 outbreak: what we know. Int. J. Infect. Dis. 0. doi:10.1016/j.ijid.2020.03.004.

Y, M., Cy, C., and Ml, H. (2007). RNA interference and antiviral therapy. World J. Gastroenterol. 13, 5169-5179. doi:10.3748/wjg.v13.i39.5169.

Yan, R., Zhang, Y., Li, Y., Xia, L., Guo, Y., and Zhou, Q. (2020). Structural basis for the recognition of the SARS-CoV-2 by full-length human ACE2. Science, eabb2762. doi:10.1126/science.abb2762.

Yang, D., and Leibowitz, J. L. (2015). The structure and functions of coronavirus genomic 3' and 5' ends. Virus Res. 206, 120-133. doi:10.1016/j.virusres.2015.02.025.

Yao, T.-T., Qian, J.-D., Zhu, W.-Y., Wang, Y., and Wang, G.-Q. (2020a). A systematic review of lopinavir therapy for SARS coronavirus and MERS coronavirus-A possible reference for coronavirus disease-19 treatment option. J. Med. Virol. n/a. doi:10.1002/jmv.25729.

Yao, X., Ye, F., Zhang, M., Cui, C., Huang, B., Niu, P., et al. (2020b). In Vitro Antiviral Activity and Projection of Optimized Dosing Design of Hydroxychloroquine for the Treatment of Severe Acute Respiratory Syndrome Coronavirus 2 (SARS-CoV-2). Clin. Infect. Dis. doi:10.1093/cid/ciaa237.

Yogo, Y., Hirano, N., Hino, S., Shibuta, H., and Matumoto, M. (1977). Polyadenylate in the Virion RNA of Mouse Hepatitis Virus. J. Biochem. (Tokyo) 82, 1103-1108. doi:10.1093/oxfordjournals.jbchem.a131782.

Zhang, H.-Z., Zhang, H., Kemnitzer, W., Tseng, B., Cinatl, Jindrich, Michaelis, M., et al. (2006). Design and Synthesis of Dipeptidyl Glutaminyl Fluoromethyl Ketones as Potent Severe Acute Respiratory Syndrome Coronovirus (SARS-CoV) Inhibitors. J. Med. Chem. 49, 1198-1201. doi:10.1021/jm0507678. 